\title{
HASIL BELAJAR TARIKH MELALUI METODE JIGSAW DAN METODE MIND MAP DI SMP MUHAMMADIYAH 13 BOYOLALI
}

\author{
Muhammad Nur Rohman, Badrus Zaman \\ IAIN Salatiga \\ nurrohmanmuhammad66@gmail.com, badruszaman43@yahoo.com
}

\begin{abstract}
Abstrak
Penelitian ini bertujuan untuk meningkatan hasil belajar Tarikh dengan menggunakan metode jigsaw dan metode mind map kelas VIII di SMP Muhammadiyah 13 Wonosegoro, Boyolali tahun ajaran 2019/2020. Penelitian ini merupakan Penelitian Tindakan Kelas dengan tahapan perencanaan, pelaksanaan, observasi, dan refleksi. Adapun metode pengumpulan data yang digunakan meliputi observasi, tes, dan dokumentasi. Analisis yang digunakan peneliti adalah membandingkan pencapaian nilai dengan Kriteria Ketuntasan Minimum (KKM) dan ditandai dengan meningkatnya kriteria ketuntasan klasikal pada setiap siklusnya. Hal ini dapat dibuktikan dengan adanya peningkatan tiap siklus yang sudah dilaksanakan. Pada pra siklus persentase ketuntasan hanya 33,3\% atau 5 peserta didik dan 10 peserta didik lainnya atau $66,7 \%$ belum tuntas. Pada Siklus I terdapat peningkatan hasil belajar menjadi $66,7 \%$ atau 10 peserta didik dan $33,3 \%$ atau 5 peserta didik yang belum tuntas. pada siklus II terjadi peningkatan menjadi 13 peserta didik yang tuntas atau $86,7 \%$ dan 2 peserta didik belum tuntas atau $13,3 \%$.
\end{abstract}

Kata Kunci: Hasil Belajar Tarikh, Metode Jigsaw, Metode Mind Map, SMP

Abstract

This study aims to improve the learning outcomes of the Date by using the jigsaw method and the mind map method of class VIII at SMP Muhammadiyah 13 Wonosegoro, Boyolali in the academic year 2019/2020. This research is a Classroom Action Research with stages of planning, implementation, observation, and reflection. The data collection methods used include observation, tests, and documentation. The analysis used by researchers is to compare the achievement of values with the Minimum completeness Criteria (KKM) and is characterized by increasing classical completeness criteria in each cycle. This can be proven by an increase in each cycle that has been carried out. In the pre cycle the percentage of completeness was only $33.3 \%$ or 5 students and 10 other students or $66.7 \%$ had not been completed. In Cycle I there was an increase in learning outcomes to $66.7 \%$ or 10 students and $33.3 \%$ or 5 unfinished students. in the second cycle there was an increase to 13 students who were completed or $86.7 \%$ and 2 students who were not yet finished or $13.3 \%$.

Keywords: Learning Outcomes, Jigsaw Method, Mind Map Method, Middle School

\section{A. PENDAHULUAN}

Pendidikan merupakan suatu proses suatu bangsa mempersiapkan generasi mudanya untuk menjalankan kehidupan dan untuk memenuhi tujuan hidup secara efektif dan efisien. Pendidikan juga adalah suatu proses suatu bangsa atau negara membina dan mengembangkan kesadaran diri diantara individu-individu [8].

Pendidikan yang dilaksanakan pada prinsipnya semua sama, yaitu memberi bimbingan agar dapat hidup mandiri sehingga dapat meneruskan dan melestarikan tradisi yang hidup di masyarakat [7]. Pendidikan merupakan interaksi antara pendidik dengan peserta didik untuk mencapai tujuan pendidikan yang berlangsung dalam lingkungan tertentu. Pendidikan diartikan sebagai usaha yang dijalankan oleh seseorang atau kelompok orang lain agar menjadi dewasa atau mencapai tingkat hidup atau penghidupan yang lebih tinggi dalam arti mental. Lebih jauh pendidikan didefinisikan sebagai suatu proses bimbingan, tuntutan atau pimpinan yang di 
dalamnya mengandung unsur-unsur seperti guru, peserta didik, tujuan, dan sebagainya [4]. Melalui pendidikan yang terprogram dan terkelola dengan baik dan intensif, titik optimum usaha pendidikan akan terwujud. Pendidikan dikatakan berhasil apabila mampu mengubah tingkah laku manusia ke arah yang positif [6].

Secara umum belajar dapat diartikan sebagai proses perubahan perilaku, akibat interaksi individu dengan lingkungan. Dengan pengertian ini kita dihadapkan pada pertanyaan pertanyaan sebagai berikut; Apakah yang dimaksud dengan perilaku?, perubahan perilaku bagaimana yang termasuk belajar?, dan apakah perubahan perilaku dapat terjadi pada setiap individu yang yang berinteraksi dengan lingkungan? [2]. Menurut R Gagne belajar adalah sebagai suatu proses di mana suatu organisme berubah perilakunya sebagai akibat dari pengalaman. Kemudian Gagne juga menyebut bahwasanya belajar itu adalah suatu proses untuk memperoleh motivasi dalam pengetahuan, keterampilan, kebiasaan dan tingkah laku [5]. Sedangkan menurut E.R. Hilgard belajar dapat diartikan sebagai suatu perubahan kegiatan reaksi terhadap lingkungan. Dalam hal ini, perubahan yang dimaksud mencakup beberapa hal, diantaranya: pengetahuan, kecakapan, tingkah laku, dan semua itu diperolah dari sebuah pengalaman [5].

Dari definisi belajar di atas, dapat disimpulkan bahwa belajar adalah sebuah perubahan yang di alami oleh individu baik secara sikap, tingkah laku, kecakapan yang diperoleh melalui sebuah pengalaman.

Islam adalah salah satu agama yang sangat menganjurkan hamba hambanya agar senantiasa untuk selalu belajar atau menuntut ilmu. firman allah SWT dalam Q.S. Al Mujadilah ayat 11.

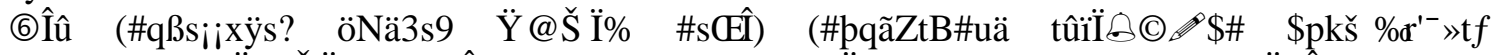

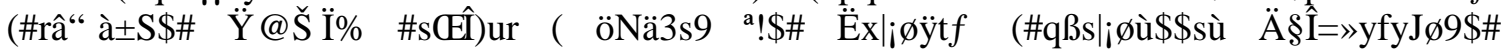

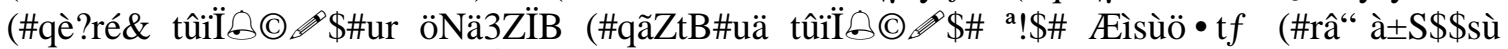

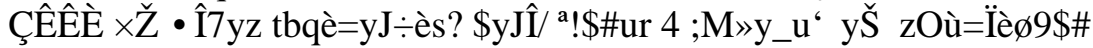
Artinya: Hai orang-orang beriman apabila kamu dikatakan kepadamu: "Berlapang-lapanglah dalam majlis", Maka lapangkanlah niscaya Allah akan memberi kelapangan untukmu. dan apabila dikatakan: "Berdirilah kamu", Maka berdirilah, niscaya Allah akan meninggikan orang-orang yang beriman di antaramu dan orang-orang yang diberi ilmu pengetahuan beberapa derajat. dan Allah Maha mengetahui apa yang kamu kerjakan (Al Qur'an dan Terjemah, Al Mujadilah ayat $11)$.

Dari dalil di atas dapat di ketahui bersama betapa Islam sangat menganjurkan umatnya untuk senantiasa menuntut ilmu atau belajar dengan tanpa batasan waktu dan usia. Dengan berilmu maka manusia akan di angkat derajatnya oleh Allah dan senantiasa selalu mendapatkan kebaikan dari ilmu tersebut, dan dengan ilmu itu pula manusia akan mendapatkan kedudukan yang mulia dan lebih tinggi daripada orang yang tidak berilmu.

Kemampuan belajar Tarikh bagi peserta didik kelas VIII SMP Muhammadiyah 13 Wonosegoro, Boyolali pada tahun 2020 pencapaian rata-rata masih di bawah nilai Kriteria Ketuntasan Minimal (KKM) yang ditetapkan sekolah yaitu 62. Hal ini diketahui setelah pengamat melakukan observasi awal pada hari sabtu tanggal 16 November 2019, pengamat melihat nilai dari hasil ulangan dari peserta didik, Terbukti dari hasil ulangan peserta didik pada mata pelajaran Tarikh yaitu dari 15 peserta didik hanya $5(33,3 \%)$ peserta didik yang dapat mencapai KKM, sedangkan $10(66,7 \%)$ peserta didik masih di bawah KKM. Presentase ketuntasan peserta didik kelas VIII masih jauh dari presentase indikator keberhasilan yaitu $85 \%$.

Kendala utama yang menjadi permasalahan utama dalam pembelajaran tarikh adalah kurang kreatifnya guru dalam melaksanakan proses pembelajaran, guru masih menggunakan metode mengajar konvensional sehingga kurang begitu menarik perhatian peserta didik dan peserta didik menjadi kurang begitu aktif dan itu menyebabkan akan rendahnya tingkat prestasi hasil belajar peserta didik kelas VIII di SMP Muhammadiyah 13 Wonosegoro, Boyolali.

Berdasarkan uraian di atas dapat diartikan bahwasanya kedudukan daripada metode pembelajaran itu sendiri, mempunyai peran yang begitu penting guna mencapai hasil belajar atau prestasi belajar yang maksimal bagi peserta didik sesuai dengan yang diharapkan. Untuk itu, peneliti bermaksud meneliti masalah tersebut dengan melakukan Penelitian Tindakan Kelas (PTK), yaitu dengan memperbaiki proses pembelajaran serta meningkatkan hasil belajar peserta didik pada mata pelajaran Tarikh dengan menggunakan metode jigsaw dan metode mind map. 
Metode Jigsaw dan metode Mind Map itu sendiri adalah sebuah metode yang mampu menarik minat peserta didik dan mampu memancing kreatifitas peserta didik itu sendiri. Metode pembelajaran ini akan diterapkan peneliti melalui penelitian tindakan kelas.

Berdasarkan latar belakang masalah tersebut di atas, dirumuskan permasalahan dalam penelitian ini yaitu: apakah penerapan metode jigsaw dan metode mind map dapat meningkatkan hasil belajar tarikh pada peserta didik kelas VIII SMP Muhammadiyah 13 Wonosegoro, Boyolali, tahun ajaran 2020?

Tujuan dari Penelitian Tindakan Kelas ini yaitu untuk mendeskripsikan bahwasanya penggunaan metode jigsaw dan metode mind map dapat Meningkatkan hasil belajar Tarikh Materi pada peserta didik kelas VIII SMP Muhammadiyah 13 Wonosegoro, Boyolali tahun ajaran 2020.

B. Metode Penelitian

Jenis penelitian ini dilakukan dengan menggunakan penelitian tindakan kelas (PTK). Penelitian tindakan kelas disebut juga dengan classroom Action Research. Menurut Rustam dan Mundilarto dalam buku Asrori mendifinisikan penelitian tindakan kelas adalah sebuah penelitian yang dilakukan oleh guru dikelasnya sendiri dengan jalan merancang, melaksankan dan merefleksikan tindakan secara kolaboratif dan partisipatif dengan tujuan untuk memperbaiki kinerjanya sebagai guru sehingga hasil belajar peserta didik dapat meingkat [1].

Dalam penelitian tindakan kelas ada empat langkah yanng biasanya dilakukan, yaitu: 1 . Perencanaan, 2. Tindakan, 3. Observasi atau Pengamatan, 4. Refleksi [1]. Penelitian ini menekankan terhadap pemahaman materi menggunakan metode jigsaw dan metode mind map dilakukan setelah mengetahui adanya permasalahan dalam hasil belajar peserta didik kelas VIII di SMP Muhammadiyah 13 Wonosegoro, Boyolali yang sebagian besar belum mencapai KKM yang ditentukkan.

Teknik mengumpulkan data yang digunakan dalam penelitian tindakan tidak hanya satu, tetapi menggunakan multi tehnik atau multi instrumen [4]. Teknik mengumpulkan data dalam penelitian ini adalah Observasi, Tes, dan Dokumentasi.

\section{Hasil dan Pembahasan}

\section{Deskripsi Data Pra Siklus}

Observasi Pra Siklus dilakukan pada bulan November dengan bertanya kepada guru PAI tentang kondisi kelas dan menemukan beberapa masalah diantaranya, yaitu kurangnya pemahaman Peserta didik dan rendahnya hasil belajar terkaiat mata pelajaran Tarikh materi pertumbuhan ilmu pengetahuan pada masa Peserta didik abbasiyah dalam. Baru sekitar 33,3\% Peserta didik atau 5 orang yang memenuhi KKM dan $66,7 \%$ atau 10 orang belum memenuhi Kriteria Ketuntasan Minimum. Dalam hal ini, Minat belajar yang kurang dari peserta didik itu sendiri yang menyebabkan pemahaman mereka menurun. Imbasnya dari kurangnya pemahaman peserta didik itulah yang mengakibatkan rendahnyah hasil belajar peserta didik itu sendiri.

Peneliti sendiri menggunakan indikator keberhasilan untuk dijadikan sebagai alat ukur keberhasilan dalam belajar yaitu yaitu KKM mata pelajaran Tarikh SMP Muhammadiyah 13 Wonosegoro Kab. Boyolali sebesar 62, serta dengan menggunakan Kriteria Ketuntasan Klasikal (KKL), yakni sebesar 85\%. Dalam Pra Siklus, peneliti menggunakan data nilai ratarata ulangan harian Peserta didik mata pelajaran Tarik

Tabel 4.1 Data Pra Siklus (Rata-Rata Nilai Ulangan Harian)

\begin{tabular}{|c|l|c|c|c|c|}
\hline \multirow{2}{*}{ NO } & \multirow{2}{*}{ Nama } & \multirow{2}{*}{ KKM } & Nilai & \multicolumn{2}{|c|}{ Keterangan } \\
\cline { 4 - 6 } & & & & Tuntas & $\begin{array}{c}\text { Tidak } \\
\text { Tuntas }\end{array}$ \\
\hline 1 & A S & 62 & 65 & $\sqrt{ }$ & \\
\hline 2 & F M & 62 & 60 & & $\sqrt{ }$ \\
\hline 3 & G Z N I & 62 & 54 & & $\sqrt{ }$ \\
\hline
\end{tabular}




\begin{tabular}{|c|l|c|c|c|c|}
\hline 4 & I E P L & 62 & 63 & $\sqrt{ }$ & \\
\hline 5 & I H & 62 & 50 & & $\sqrt{ }$ \\
\hline 6 & I M & 62 & 65 & $\sqrt{ }$ & \\
\hline 7 & M A & 62 & 55 & & $\sqrt{ }$ \\
\hline 8 & M Kl F & 62 & 60 & & $\sqrt{ }$ \\
\hline 9 & M K & 62 & 64 & $\sqrt{ }$ & \\
\hline 10 & N A & 62 & 52 & & $\sqrt{ }$ \\
\hline 11 & P A & 62 & 56 & & $\sqrt{ }$ \\
\hline 12 & R K & 62 & 65 & $\sqrt{ }$ & $\sqrt{ }$ \\
\hline 13 & S R & 62 & 57 & & $\sqrt{ }$ \\
\hline 14 & S & 62 & 50 & & $\mathbf{1 0}$ \\
\hline 15 & W B W & 62 & 54 & & $\mathbf{6 6 . 7 \%}$ \\
\hline \multicolumn{7}{|c|}{ Jumlah } & & $\mathbf{8 7 0}$ & $\mathbf{5}$ & \\
\hline
\end{tabular}

Dari tabel di atas, dapat diketahui bahwasanya persentase ketuntasan hanya 33,3\% saja. Peserta didik yang tuntas baru mencapai 5 orang dan 10 peserta didik lainnya belum tuntas atau $66,7 \%$ belum memenuhi nilai ketuntasan minimum. Nilai rata-rata kelas diketahui juga masih rendah, hanya berkisar di angka 58, meskipun lebih dari setengah peserta didik yang sudah tuntas. Akan tetapi, Ini menunjukkan bahwasanya hasil belajar dari peserta didik kelas VIII SMP Muhammadiyah 13 Wonosegoro masih sangatlah rendah dan belum memenuhi ketuntasan klasikal $85 \%$ dari seluruh peserta didik.

\section{Deskripsi Siklus 1}

Proses pembelajaran pada siklus I melalui metode jigsaw dan metode mind map, sudah ada Peningkatan hasil belajar peserta didik meskipun belum memenuhi target yang di harapkan oleh peneliti. Untuk melihat hasil belajar Peserta didik, peneliti membuat tiga penilaian yang akan dinilai oleh guru yaitu, penilaian pengetahuan, penilaian sikap, dan penilaian diskusi serta presentasi. Sedangkan dari sudut pandang peneliti berupa lembar pengamatan guru dan Peserta didik.

\section{a. Hasil Tes}

Hasil tes peserta didik setelah pembelajaran menggunakan metode jigsaw dan metode mind map dengan materi sejarah pertumbuhan ilmu pengetahuan pada masa Peserta didik abbasiyah. Rincian data nilai pada siklus I adalah sebagai berikut:

Tabel 4.2 Hasil Tes Peserta didik Siklus I

\begin{tabular}{|c|l|c|c|c|c|}
\hline \multirow{2}{*}{ NO } & \multirow{2}{*}{ Nama } & \multirow{2}{*}{ KKM } & \multirow{2}{*}{ Nilai } & \multicolumn{2}{|c|}{ Keterangan } \\
\cline { 5 - 6 } & & & & Tuntas & Tidak Tuntas \\
\hline 1 & A S & 62 & 80 & $\sqrt{ }$ & \\
\hline 2 & F M & 62 & 55 & & $\sqrt{ }$ \\
\hline
\end{tabular}




\begin{tabular}{|c|c|c|c|c|c|}
\hline 3 & G Z N I & 62 & 65 & $\sqrt{ }$ & \\
\hline 4 & IE P L & 62 & 80 & $\sqrt{ }$ & \\
\hline 5 & I H & 62 & 40 & & $\sqrt{ }$ \\
\hline 6 & I M & 62 & 70 & $\sqrt{ }$ & \\
\hline 7 & M A & 62 & 65 & $\sqrt{ }$ & \\
\hline 8 & M K F & 62 & 70 & $\sqrt{ }$ & \\
\hline 9 & M K & 62 & 70 & $\sqrt{ }$ & \\
\hline 10 & N A & 62 & 40 & & $\sqrt{ }$ \\
\hline 11 & P A & 62 & 70 & $\sqrt{ }$ & \\
\hline 12 & R K & 62 & 70 & $\sqrt{ }$ & \\
\hline 13 & S R & 62 & 65 & $\sqrt{ }$ & \\
\hline 14 & $\mathrm{~S}$ & 62 & 55 & & $\sqrt{ }$ \\
\hline 15 & W B w & 62 & 55 & & $\sqrt{ }$ \\
\hline \multicolumn{3}{|c|}{ Jumlah } & 950 & 10 & 5 \\
\hline \multicolumn{3}{|c|}{ Nilai Rata-rata } & 63 & & \\
\hline \multicolumn{3}{|c|}{ Persentase } & & $66.7 \%$ & $33.3 \%$ \\
\hline
\end{tabular}

Berdasarkan hasil tes pada siklus I diperoleh data seperti pada tabel diatas. Peserta didik yang tuntas sebanyak 10 orang atau $66,7 \%$ dan Peserta didik yang tidak tuntas sebanyak 5 orang atau $33.3 \%$ dengan nilai rata-rata 63. Dibandingkan dengan data nilai pra siklus, pada siklus I sudah mengalami Peningkatan. Peserta didik yang nilainya melebihi KKM meningkat sebanyak 5 orang. Namun, hasil tes tersebut belum memenuhi ketuntasan klasikal sebanyak $85 \%$ dari total Peserta didik sesuai yang diharapkan oleh peneliti. Maka dari itu, peneliti harus melanjutkan penelitian ke siklus II agar dapat mencapai sesuai yang diaharapkan oleh peneliti itu sendiri.

b. Lembar Pengamatan Guru Siklus 1

Tabel 4.3 Hasil Pengamatan Guru Siklus I

\begin{tabular}{|l|l|l|l|l|l|}
\hline \multirow{2}{*}{ No } & \multicolumn{1}{|c|}{ Aspek yang diamati* } & \multicolumn{3}{|c|}{ Nilai } \\
\cline { 3 - 6 } & & K & C & B & SB \\
\hline A & $\begin{array}{l}\text { Kemampuan guru dalam membuka } \\
\text { pelajaran }\end{array}$ & & & & \\
\hline 1 & Menarik perhatian Peserta didik & & $\sqrt{ }$ & \\
\hline 2 & $\begin{array}{l}\text { Memberikan motivasi awal dan apresepsi } \\
\text { (berkaitan dengan materi) }\end{array}$ & & & $\sqrt{ }$ & \\
\hline 3 & Menyampaikan tujuan pembelajaran & & & $\sqrt{ }$ & \\
\hline B & Sikap guru dalam proses pembelajaran & & & & \\
\hline
\end{tabular}




\begin{tabular}{|c|c|c|c|c|}
\hline 1 & Kejelasan artikulasi suara & & & $\sqrt{ }$ \\
\hline 2 & $\begin{array}{l}\text { Variasi gerakan tidak mengganggu perhatian } \\
\text { Peserta didik }\end{array}$ & & $\sqrt{ }$ & \\
\hline 3 & Antusiasme dalam penampilan mengajar & & $\sqrt{ }$ & \\
\hline C & Penguasaan bahan ajar & & & \\
\hline 1 & $\begin{array}{l}\text { Bahan ajar disampaikan sesuai dengan } \\
\text { langkah-langkah dalam RPP }\end{array}$ & $\sqrt{ }$ & & \\
\hline 2 & Kejelasan dalam menjelaskan materi & & $\sqrt{ }$ & \\
\hline 3 & Kejelasan dalam memberikan contoh & $\sqrt{ }$ & & \\
\hline 4 & $\begin{array}{l}\text { Memiliki wawasan yang luas dalam } \\
\text { menyampaikan bahan ajar }\end{array}$ & & $\sqrt{ }$ & \\
\hline $\mathbf{D}$ & Kegiatan belajar mengajar & & & \\
\hline 1 & Metode yang dipakai sesuai RPP & & & $\sqrt{ }$ \\
\hline 2 & $\begin{array}{l}\text { Penyajian bahan ajar sesuai dengan indikator } \\
\text { dan tujuan yang telah ditetapkan }\end{array}$ & & $\sqrt{ }$ & \\
\hline 3 & Merespon pertanyaan Peserta didik & & $\sqrt{ }$ & \\
\hline 4 & Ketepatan penggunaan alokasi waktu & & $\sqrt{1}$ & \\
\hline $\mathbf{E}$ & $\begin{array}{l}\text { Kemampuan menggunakan media } \\
\text { pembelajaran }\end{array}$ & & & \\
\hline 1 & $\begin{array}{l}\text { Pemahaman terhadap metode yang telah } \\
\text { disiapkan }\end{array}$ & & $\sqrt{ }$ & \\
\hline 2 & Menggunkan metode secara efektif dan efisien & & $\sqrt{ }$ & \\
\hline 3 & $\begin{array}{l}\text { Melibatkan Peserta didik dalam pemanfaatan } \\
\text { metode }\end{array}$ & & $\sqrt{ }$ & \\
\hline $\mathbf{F}$ & $\begin{array}{l}\text { Kemampuan menutup kegiatan } \\
\text { pembelajaran }\end{array}$ & & & \\
\hline 1 & $\begin{array}{l}\text { Guru memberi kesempatan Peserta didik untuk } \\
\text { bertanya }\end{array}$ & & $\sqrt{ }$ & \\
\hline 2 & $\begin{array}{l}\text { Melakukan evaluasi pembelajaran sesuai } \\
\text { dengan RPP }\end{array}$ & & $\sqrt{ }$ & \\
\hline 3 & $\begin{array}{l}\text { Memberikan kesimpulan kegiatan } \\
\text { pembelajaran }\end{array}$ & & $\sqrt{ }$ & \\
\hline \multicolumn{2}{|c|}{ Jumlah } & 2 & 16 & 2 \\
\hline & Total skor & \multicolumn{3}{|c|}{60} \\
\hline
\end{tabular}




\begin{tabular}{|c|c|}
\hline Kategori & Baik \\
\hline
\end{tabular}

Keterangan:

SB : 4 (Sangat baik)

B : 3 (Baik)

C : 2 (Cukup)

$\mathrm{K} \quad$ : 1 (Kurang)

Rentang Kategori:

Kurang : Jika total perolehan skor $1-20$

Cukup : Jika total perolehan skor $21-40$

Baik : Jika total perolehan skor $41-60$

Sangat Baik : Jika total perolehan skor $61-80$

Setelah dilakukannya peneitian pada kegiatan pembelajaran siklus I, didapat hasil pengamatan guru. Hasilnya adalah dari 20 kriteria yang dinilai, terdapat 2 poin cukup, 16 poin baik, dan 2 poin sangat baik. Total skor yang diperoleh guru adalah 60 dan masuk dalam kategori baik. Namun harus ditingkatkan pada siklus selanjutnya.

\section{c. Lembar Pengamatan Peserta Didik}

Tabel 4.4 Hasil Pengamatan Peserta Didik Siklus I

\begin{tabular}{|c|c|c|c|c|c|c|c|c|c|c|c|c|c|}
\hline \multirow{3}{*}{ No } & \multirow{3}{*}{$\begin{array}{c}\text { Peserta } \\
\text { didik }\end{array}$} & \multicolumn{12}{|c|}{ Aspek yang diamati } \\
\hline & & \multicolumn{4}{|c|}{ Pengetahuan } & \multicolumn{4}{|c|}{ Afektif } & \multicolumn{4}{|c|}{ Psikomotor } \\
\hline & & $\mathbf{K}$ & $\mathbf{C}$ & B & SB & $\mathbf{K}$ & $\mathbf{C}$ & B & SB & $\mathbf{K}$ & $\mathrm{C}$ & $\mathbf{B}$ & SB \\
\hline 1 & $\begin{array}{l}\text { Anis } \\
\text { Sanjaya }\end{array}$ & & & & $\sqrt{ }$ & & & & $\sqrt{ }$ & & & & $\sqrt{ }$ \\
\hline 2 & $\begin{array}{l}\text { Febrianita } \\
\text { Muntiasih }\end{array}$ & & $\sqrt{ }$ & & & & & $\sqrt{ }$ & & & $\sqrt{ }$ & & \\
\hline 3 & $\begin{array}{l}\text { Galang } \\
\text { Zaki Nur I }\end{array}$ & & $\sqrt{ }$ & & & & $\sqrt{ }$ & & & & $\sqrt{ }$ & & \\
\hline 4 & $\begin{array}{l}\text { Intan Eka } \\
\text { Puji Lestari }\end{array}$ & & & & $\sqrt{ }$ & & & & $\sqrt{ }$ & & & & $\sqrt{ }$ \\
\hline 5 & $\begin{array}{l}\text { Iqbal } \\
\text { Hanafi }\end{array}$ & & $\sqrt{ }$ & & & & $\sqrt{ }$ & & & & $\sqrt{ }$ & & \\
\hline 6 & $\begin{array}{l}\text { Isnaini } \\
\text { Maisaroh }\end{array}$ & & & $\sqrt{ }$ & & & & $\sqrt{ }$ & & & & $\sqrt{ }$ & \\
\hline 7 & $\begin{array}{l}\text { Muhammad } \\
\text { Arif }\end{array}$ & & & $\sqrt{ }$ & & & & $\sqrt{ }$ & & & $\sqrt{ }$ & & \\
\hline 8 & $\begin{array}{l}\text { Muhammad } \\
\text { Kanzul F }\end{array}$ & & & $\sqrt{ }$ & & & & $\sqrt{ }$ & & & & $\sqrt{ }$ & \\
\hline 9 & $\begin{array}{l}\text { Mutiara } \\
\text { Khasanah }\end{array}$ & & & $\sqrt{ }$ & & & & $\sqrt{ }$ & & & & $\sqrt{ }$ & \\
\hline 10 & $\begin{array}{l}\text { Nursyam } \\
\text { Andriani }\end{array}$ & & $\sqrt{ }$ & & & & $\sqrt{ }$ & & & & $\sqrt{ }$ & & \\
\hline 11 & $\begin{array}{l}\text { Putri } \\
\text { Astutik }\end{array}$ & & & $\sqrt{ }$ & & & & $\sqrt{ }$ & & & & $\sqrt{ }$ & \\
\hline
\end{tabular}




\begin{tabular}{|c|c|c|c|c|c|c|c|c|c|c|c|c|c|}
\hline 12 & $\begin{array}{l}\text { Renata } \\
\text { Kristiani }\end{array}$ & & & $\sqrt{ }$ & & & & $\sqrt{ }$ & & & & $\checkmark$ & \\
\hline 13 & $\begin{array}{l}\text { Slamet } \\
\text { Riyadi }\end{array}$ & & $\sqrt{ }$ & & & & $\sqrt{ }$ & & & & $\sqrt{ }$ & & \\
\hline 14 & Sholeh & & $\sqrt{ }$ & & & & $\sqrt{ }$ & & & & $\sqrt{ }$ & & \\
\hline 15 & $\begin{array}{ll}\text { Wiji } & \text { Bayu } \\
\text { W } & \end{array}$ & & $\sqrt{ }$ & & & & $\sqrt{ }$ & & & & $\sqrt{ }$ & & \\
\hline & Jumlah & $\mathbf{0}$ & 7 & 6 & 2 & $\mathbf{0}$ & 6 & 7 & 2 & $\mathbf{0}$ & 8 & 5 & 2 \\
\hline & Total Skor & \multicolumn{4}{|c|}{40} & \multicolumn{4}{|c|}{39} & \multicolumn{4}{|c|}{39} \\
\hline & Kategori & \multicolumn{4}{|c|}{ Baik } & \multicolumn{4}{|c|}{ Baik } & \multicolumn{4}{|c|}{ Baik } \\
\hline
\end{tabular}

Keterangan:

SB : 4 (Sangat baik)

B : 3 (Baik)

C : 2 (Cukup)

$\mathrm{K} \quad: 1$ (Kurang)

Rentang Kategori:

Kurang : Jika total perolehan skor $1-15$

Cukup : Jika total perolehan skor 16-30

Baik : Jika total perolehan skor $31-45$

Sangat Baik : Jika total perolehan skor 46-60

Berdasarkan tabel diatas dapat dilihat bahwa aspek pengetahuan, afektif, dan psikomotorik pada siklus I sudah tergolong bagus. Dilihat dari total skor pada masingmasing aspek yang mencapai kategori baik. Namun harus tetap dipertahankan dan bila memungkinkan dapat ditingkatkan pada siklus berikutnya yaitu siklus II agar lebih optimal.

\section{d. Hasil Pengamatan Guru dan Peserta didik}

Hasil pengamatan yang dilakukan oleh guru dan peserta didik dalam kegiatan pembelajaran siklus I didasari pada pengamatan pembelajaran siklus I terhadap kegiatan guru dan peserta didik. Peneliti menjumpai hambatan-hambatan yang dihadapi ketika dalam proses kegiatan pembelajaran berlangsung. Hambatan-hambatan tersebut meliputi:

1. Guru belum sepenuhnya bisa mengondisikan keadaan kelas.

2. Peserta didik masih belum begitu mengetahuai dan paham tentang metode yang dipakai oleh guru.

3. Kegiatan belajar mengajar belum sepenuhnya sesuai dengan rencana peneliti.

Berdasarkan hambatan-hambatan yang di jumpai diatas, maka peneliti melakukan rencana perbaikan sebagai berikut:

1. Guru lebih memberi ketegasan pada Peserta didik dalam pengondisian kelas.

2. Guru lebih bisa mengontrol perhatian Peserta didik, memporsikan perhatian Peserta didik terhadap metode dan materi secara berimbang.

3. Guru lebih teliti dalam melaksanakan langkah-langkah pembelajaran, sehingga tidak ada bagian materi yang terlewat.

4. Guru lebih memberi penjelasan dalam pengaturan dan tugas masing masing anggota kelompok.

\section{Deskripsi Siklus II}

Pada siklus II, peneliti telah menyiapkan perangkat pembelajaran yang terdiri dari rencana pelaksanaan pembelajaran siklus II, kertas untuk membuat resume dalam bentuk Mind Map, soal evaluasi, dan lembar pengamatan untuk guru dan peserta didik.

Hambatan-hambatan yang terjadi pada siklus I diperbaiki pada siklus II. Hasil pengamatan yang dilakukan pada siklus II, peneliti mendapati bahwasanya guru guru sudah mampu mengatasi hambatan-hambatan yang terjadi pada siklus I dan bahkan guru mampu 
menguasai peserta didik dan menguasai kelas. Sehingga peserta didik lebih tertarik dan tertib dalam proses pembelajaran yang dilakukan pada Siklus II.

a. Hasil Tes

Tabel 4.5 Hasil Tes Siklus II

\begin{tabular}{|c|c|c|c|c|c|}
\hline \multirow{3}{*}{ NO } & \multirow{3}{*}{ Nama } & \multirow{3}{*}{ KKM } & \multirow{3}{*}{ Nilai } & \multirow{2}{*}{\multicolumn{2}{|c|}{ Keterangan }} \\
\hline & & & & & \\
\hline & & & & Tuntas & $\begin{array}{l}\text { Tidak } \\
\text { Tuntas }\end{array}$ \\
\hline 1 & A S & 62 & 85 & $\sqrt{ }$ & \\
\hline 2 & F M & 62 & 65 & $\sqrt{ }$ & \\
\hline 3 & G Z N I & 62 & 65 & $\sqrt{ }$ & \\
\hline 4 & IE P L & 62 & 80 & $\sqrt{ }$ & \\
\hline 5 & I H & 62 & 50 & & $\sqrt{ }$ \\
\hline 6 & I M & 62 & 70 & $\sqrt{ }$ & \\
\hline 7 & M A & 62 & 70 & $\sqrt{ }$ & \\
\hline 8 & M K F & 62 & 70 & $\sqrt{ }$ & \\
\hline 9 & M K & 62 & 70 & $\sqrt{ }$ & \\
\hline 10 & $\mathrm{NA}$ & 62 & 40 & & $\sqrt{ }$ \\
\hline 11 & P A & 62 & 70 & $\sqrt{ }$ & \\
\hline 12 & R K & 62 & 80 & $\sqrt{ }$ & \\
\hline 13 & S R & 62 & 65 & $\sqrt{ }$ & \\
\hline 14 & $\mathrm{~S}$ & 62 & 65 & $\sqrt{ }$ & \\
\hline 15 & W B W & 62 & 65 & $\sqrt{ }$ & \\
\hline \multicolumn{3}{|c|}{ Jumlah } & 1010 & 13 & 2 \\
\hline \multicolumn{3}{|c|}{ Nilai Rata-rata } & 67 & & \\
\hline \multicolumn{3}{|c|}{ Persentase } & & $86.7 \%$ & $13.3 \%$ \\
\hline
\end{tabular}

Berdasarkan hasil tes pada siklus II diperoleh data seperti pada tabel diatas. Peserta didik yang tuntas sebanyak 13 orang atau $86,7 \%$ dan Peserta didik yang tidak tuntas sebanyak 2 orang atau $13.3 \%$ dengan nilai rata-rata 67 . Hal ini menunjukkan bahwa dari siklus 1 ke siklus II mengalami peningkatan hasil belajar dan sudah sesuai dengan target yang diharapkan oleh peneliti.

b. Lembar Hasil Pengamatan Guru Siklus II

Tabel 4.6 Hasil Pengamatan Peserta Didik Siklus II

\begin{tabular}{|c|c|c|c|c|c|}
\hline \multirow{2}{*}{ No } & \multirow{2}{*}{ Aspek yang diamati* } & \multicolumn{4}{|c|}{ Nilai } \\
\hline & & $\mathrm{K}$ & $\mathrm{C}$ & $\mathrm{B}$ & SB \\
\hline $\mathbf{A}$ & $\begin{array}{l}\text { Kemampuan guru dalam membuka } \\
\text { pelajaran }\end{array}$ & & & & \\
\hline 1 & Menarik perhatian Peserta didik & & & $\sqrt{ }$ & \\
\hline
\end{tabular}




\begin{tabular}{|c|c|c|c|c|}
\hline 2 & $\begin{array}{l}\text { Memberikan motivasi awal dan apresepsi } \\
\text { (berkaitan dengan materi) }\end{array}$ & & & $\sqrt{ }$ \\
\hline 3 & Menyampaikan tujuan pembelajaran & & $\sqrt{ }$ & \\
\hline $\mathbf{B}$ & Sikap guru dalam proses pembelajaran & & & \\
\hline 1 & Kejelasan artikulasi suara & & & $\sqrt{ }$ \\
\hline 2 & $\begin{array}{l}\text { Variasi gerakan tidak mengganggu perhatian } \\
\text { Peserta didik }\end{array}$ & & $\sqrt{ }$ & \\
\hline 3 & Antusiasme dalam penampilan mengajar & & $\sqrt{ }$ & \\
\hline $\mathbf{C}$ & Penguasaan bahan ajar & & & \\
\hline 1 & $\begin{array}{l}\text { Bahan ajar disampaikan sesuai dengan } \\
\text { langkah-langkah dalam RPP }\end{array}$ & & & $\sqrt{ }$ \\
\hline 2 & Kejelasan dalam menjelaskan materi & & $\sqrt{ }$ & \\
\hline 3 & Kejelasan dalam memberikan contoh & & $\sqrt{ }$ & \\
\hline 4 & $\begin{array}{l}\text { Memiliki wawasan yang luas dalam } \\
\text { menyampaikan bahan ajar }\end{array}$ & & $\sqrt{ }$ & \\
\hline D & Kegiatan belajar mengajar & & & \\
\hline 1 & Metode yang dipakai sesuai RPP & & & $\sqrt{ }$ \\
\hline 2 & $\begin{array}{l}\text { Penyajian bahan ajar sesuai dengan indikator } \\
\text { dan tujuan yang telah ditetapkan }\end{array}$ & & $\sqrt{ }$ & \\
\hline 3 & Merespon pertanyaan Peserta didik & & $\sqrt{ }$ & \\
\hline 4 & Ketepatan penggunaan alokasi waktu & & $\sqrt{ }$ & \\
\hline $\mathbf{E}$ & $\begin{array}{l}\text { Kemampuan menggunakan media } \\
\text { pembelajaran }\end{array}$ & & & \\
\hline 1 & $\begin{array}{l}\text { Pemahaman terhadap metode yang telah } \\
\text { disiapkan }\end{array}$ & & $\sqrt{ }$ & \\
\hline 2 & Menggunkan metode secara efektif dan efisien & & $\sqrt{ }$ & \\
\hline 3 & $\begin{array}{l}\text { Melibatkan Peserta didik dalam pemanfaatan } \\
\text { metode }\end{array}$ & & $\sqrt{ }$ & \\
\hline $\mathbf{F}$ & $\begin{array}{l}\text { Kemampuan menutup kegiatan } \\
\text { pembelajaran }\end{array}$ & & & \\
\hline 1 & $\begin{array}{l}\text { Guru memberi kesempatan Peserta didik untuk } \\
\text { bertanya }\end{array}$ & & $\sqrt{ }$ & \\
\hline 2 & $\begin{array}{l}\text { Melakukan evaluasi pembelajaran sesuai } \\
\text { dengan RPP }\end{array}$ & & $\sqrt{ }$ & \\
\hline 3 & $\begin{array}{l}\text { Memberikan kesimpulan kegiatan } \\
\text { pembelajaran }\end{array}$ & & $\sqrt{ }$ & \\
\hline \multicolumn{2}{|c|}{ Jumlah } & $\mathbf{0}$ & 16 & 4 \\
\hline \multicolumn{2}{|r|}{ Total skor } & \multicolumn{3}{|c|}{64} \\
\hline \multicolumn{2}{|r|}{ Kategori } & \multicolumn{3}{|c|}{ Sangat Baik } \\
\hline
\end{tabular}

Keterangan:

SB : 4 (Sangat baik)

B : 3 (Baik)

C : 2 (Cukup)

K : 1 (Kurang)

Rentang Kategori:

Kurang : Jika total perolehan skor $1-20$

Cukup : Jika total perolehan skor $21-40$

Baik : Jika total perolehan skor $41-60$

Sangat Baik : Jika total perolehan skor $61-80$

Setelah dilakukannya peneitian pada kegiatan pembelajaran siklus II, didapat hasil pengamatan guru. Hasilnya adalah dari 20 kriteria yang dinilai, terdapat 16 poin baik, dan 4 poin sangat baik. Total skor yang diperoleh guru adalah 64 dan masuk dalam kategori Sangat baik.

c. Lembar Pengamatan Peserta didik Siklus II 
Tabel 4.7 Hasil Pengamatan Peserta didik Siklus II

\begin{tabular}{|c|c|c|c|c|c|c|c|c|c|c|c|c|c|}
\hline \multirow{3}{*}{ No } & \multirow{3}{*}{$\begin{array}{c}\text { Peserta } \\
\text { didik }\end{array}$} & \multicolumn{12}{|c|}{ Aspek yang diamati } \\
\hline & & \multicolumn{4}{|c|}{ Pengetahuan } & \multicolumn{4}{|c|}{ Afektif } & \multicolumn{4}{|c|}{ Psikomotor } \\
\hline & & $\mathbf{K}$ & $\mathrm{C}$ & B & SB & $\mathbf{K}$ & $\mathrm{C}$ & B & SB & $\mathbf{K}$ & $\mathrm{C}$ & B & SB \\
\hline 1 & $\begin{array}{l}\text { Anis } \\
\text { Sanjaya }\end{array}$ & & & & $\sqrt{ }$ & & & & $\sqrt{ }$ & & & & $\sqrt{ }$ \\
\hline 2 & $\begin{array}{l}\text { Febrianita } \\
\text { Muntiasih }\end{array}$ & & & $\sqrt{ }$ & & & & $\sqrt{ }$ & & & & $\sqrt{ }$ & \\
\hline 3 & $\begin{array}{l}\text { Galang } \\
\text { Zaki Nur I }\end{array}$ & & & $\sqrt{ }$ & & & & $\sqrt{ }$ & & & & $\sqrt{ }$ & \\
\hline 4 & $\begin{array}{l}\text { Intan Eka } \\
\text { Puji } \\
\text { Lestari }\end{array}$ & & & & $\sqrt{ }$ & & & & $\sqrt{ }$ & & & & $\sqrt{ }$ \\
\hline 5 & $\begin{array}{l}\text { Iqbal } \\
\text { Hanafi }\end{array}$ & & $\sqrt{ }$ & & & & $\sqrt{ }$ & & & & $\sqrt{ }$ & & \\
\hline 6 & $\begin{array}{l}\text { Isnaini } \\
\text { Maisaroh }\end{array}$ & & & $\sqrt{ }$ & & & & & $\sqrt{ }$ & & & & $\sqrt{ }$ \\
\hline 7 & $\begin{array}{l}\text { Muhamma } \\
\text { d Arif }\end{array}$ & & & $\sqrt{ }$ & & & & $\sqrt{ }$ & & & & $\sqrt{ }$ & \\
\hline 8 & $\begin{array}{l}\text { Muhamma } \\
\text { d Kanzul F }\end{array}$ & & & & $\sqrt{ }$ & & & & $\sqrt{ }$ & & & & $\sqrt{ }$ \\
\hline 9 & $\begin{array}{l}\text { Mutiara } \\
\text { Khasanah }\end{array}$ & & & $\sqrt{ }$ & & & & $\sqrt{ }$ & & & & & $\sqrt{ }$ \\
\hline 10 & $\begin{array}{l}\text { Nursyam } \\
\text { Andriani }\end{array}$ & & $\sqrt{ }$ & & & & $\sqrt{ }$ & & & & $\sqrt{ }$ & & \\
\hline 11 & $\begin{array}{l}\text { Putri } \\
\text { Astutik }\end{array}$ & & & $\sqrt{ }$ & & & & $\sqrt{ }$ & & & & $\sqrt{ }$ & \\
\hline 12 & $\begin{array}{l}\text { Renata } \\
\text { Kristiani }\end{array}$ & & & & $\sqrt{ }$ & & & & $\sqrt{ }$ & & & & $\sqrt{ }$ \\
\hline 13 & $\begin{array}{l}\text { Slamet } \\
\text { Riyadi }\end{array}$ & & & $\sqrt{ }$ & & & & $\sqrt{ }$ & & & & $\sqrt{ }$ & \\
\hline 14 & Sholeh & & & $\sqrt{ }$ & & & & $\sqrt{ }$ & & & & $\sqrt{ }$ & \\
\hline 15 & $\begin{array}{l}\text { Wiji Bayu } \\
\text { W }\end{array}$ & & & $\sqrt{ }$ & & & & $\sqrt{ }$ & & & & $\sqrt{ }$ & \\
\hline \multicolumn{2}{|r|}{ Jumlah } & $\mathbf{0}$ & 2 & 9 & 4 & $\mathbf{0}$ & 2 & 8 & 5 & $\mathbf{0}$ & 2 & 7 & 6 \\
\hline \multirow{2}{*}{\multicolumn{2}{|c|}{ Total Skor }} & \multicolumn{4}{|c|}{47} & \multicolumn{4}{|c|}{48} & \\
\hline & & & an & at $\mathrm{B}$ & & & ang & t B & & \multicolumn{4}{|c|}{$\frac{49}{\text { Sangat Baik }}$} \\
\hline
\end{tabular}

Keterangan:

SB : 4 (Sangat baik)

B : 3 (Baik)

C : 2 (Cukup)

$\mathrm{K} \quad$ : 1 (Kurang)

Rentang Kategori:

Kurang : Jika total perolehan skor $1-15$

Cukup : Jika total perolehan skor $16-30$

Baik: Jika total perolehan skor 31 - 45

Sangat Baik : Jika total perolehan skor 46-60

Pada siklus II ini terjadi Peningkatan pada ketiga aspek yang diamati oleh peneliti.

Perolehan skor yang diperoleh juga cenderung mengalami peningkatan dari pada siklus sebelumnya dan banyaknya peserta didik yang telah mencapai kriteria baik dan sangat baik 
semakin banyak atau meningkat. Hal ini berarti bahwasanya pembelajaran yang dilakukan pada siklus II ini berjalan baik dan sesuai dengan apa yang telah di rencanakan dan diharapkan oleh peneliti.

\section{Kesimpulan}

Berdasarkan Penelitian Tindakan Kelas yang dilakukan di SMP Muhammadiyah 13 Wonosegoro, Boyolali dapat disimpulkan bahwa penggunaan metode Jigsaw dan metode Mind Map dapat meningkatkan hasil belajar mata pelajaran Tarikh. Hal ini dapat dibuktikan dengan adanya Peningkatan tiap siklus yang sudah dilaksanakan. Pada Pra Siklus persentase ketuntasan hanya 33,3\% atau 5 peserta didik dan 10 Peserta Didik lainnya atau 66,7\% belum tuntas, dengan nilai rata-rata 58. Pada Siklus I terdapat peningkatan hasil belajar menjadi 66,7\% atau 10 peserta didik dan 33,3\% atau 5 peserta didik yang belum tuntas, dengan nilai rata-rata 63. Pada Siklus II terjadi peningkatan menjadi 13 peserta didik yang tuntas atau 86,7\% dan 2 Peserta Didik belum tuntas atau $13,3 \%$ dengan nilai rata-rata 67.

Hal tersebut menunjukkan bahwasanya ketuntasan hasil belajar peserta didik pada Siklus II telah mencapai Kriteria Ketuntasan Klasikal yang telah ditentukan sebesar 85\% dari jumlah seluruh peserta didik yang ada di kelas. Dengan demikian, dapat disimpulkan bahwasanya untuk Penelitian Tindakan Kelas (PTK) menggunakan metode Jigsaw dan metode Mind Map Mata Pelajaran Tarikh pada peserta didik kelas VIII di SMP Muhammadiyah 13 Wonosegoro Kab Boyolali tahun pelajaran 2019/2020 dinyatakan berhasil.

\section{Daftar Pustaka}

[1] Asrori, Muhammad. Penelitian Tindakan Kelas. Bandung: CV. Wacana Prima. 2009: hal 5-100.

[2] Laefudin. Belajar dan Pembelajaran. Sleman: CV Budi Utama. 2013: hal. 2.

[3] Hasbullah. 2006. Dasar-dasar Ilmu Pendidikan. Jakarta: Raja Grafindo Persada.

[4] Sukmadinata, Nana Syaodih. Metode Penelitian Pendidikan. Bandung: PT Remaja Rosdakarya. 2010: hal. 151

[5] Susanto, Ahmad. Teori Belajar dan Pembelajaran di Sekolah Dasar. Jakarta: Kencana Prenada Media Group. 2013: hal. 2

[6] Rochimah, Nur Apriliya \& Badrus Zaman. Pendidikan Moral Anak Jalanan. Yogyakarta: Trussmedia Grafika. 2018: hal. 31.

[7] Zaman, Badrus. Pendidikan Akhlak pada Anak Jalanan di Surakarta. Jurnal Inspirasi Undaris Ungaran 2018: Vol. 2 No. 2. hal. 130

[8] Zaman, Badrus. Urgensi Pendidikan Karakter yang sesuai dengan Falsafah Bangsa Indonesia. Jurnal Al Ghazali STAINU Purworejo. 2019: Vol. 2 No. 1. hal. 19-20. 